\title{
Implementasi Packet Filtering Menggunakan Metode Extended Access Control List (ACL) Pada Protokol EIGRP
}

\author{
Muhammad Hafizhan, Moh. Iwan Wahyuddin, Ratih Titi Komalasari \\ Fakultas Teknologi Komunikasi dan Informatika, Informatika, Universitas Nasional, Jakarta, Indonesia \\ Email: ${ }^{1}$ muhammadhafizhan0@gmail.com, ${ }^{2}$ iwan_wyd@yahoo.com, ${ }^{3}$ ukhuwahku01@gmail.com
}

\begin{abstract}
Abstrak-Menjaga aspek keamanan merupakan hal penting untuk mengelola kinerja jaringan sehingga dapat memberikan layanan optimal bagi penggunanya. Sulitnya mengatur pengiriman data di jaringan lokal (LAN) antar dua divisi atau lebih, tanpa mengganggu lalu lintas data pada divisi lain merupakan permasalahan utama pada perusahaan. Salah satu usaha yang dapat dilakukan adalah dengan menerapkan access list extended yang merupakan salah satu bagian dari metode Access Control List (ACL). ACL extended nantinya akan digunakan sebagai filter paket (packet filtering) bagi masing-masing ruang kerja, seperti ruang kerja karyawan dan ruang kerja manager. ACL nantinya akan berjalan pada protokol EIGRP. pada protokol EIGRP akan dilakukan pengujian dengan parameter delay, dan dari hasil yang di dapatkan bahwa dengan menerapkan metode ACL pada EIGRP dapat memberikan ketersediaan jaringan yang memiliki delay lebih kecil dengan ratarata sebesar 90,4 ms.
\end{abstract}

Kata Kunci: ACL, Access Control List, Penyaringan Paket, ACL Extended, Access List.

\begin{abstract}
Maintaining security aspects is important for managing network performance so that it can provide optimal services for its users. The difficulty of managing data transmission on a local network (LAN) between two or more divisions, without disrupting data traffic on other divisions, is a major problem for companies. One effort that can be done is to implement an extended access list which is one part of the Access Control List (ACL) method. The extended ACL will be used as packet filtering for each workspace, such as the employee workspace and the manager's workspace. ACL will later run on the EIGRP protocol. the EIGRP protocol will be tested with delay parameters, and the results obtained that by applying the ACL method on EIGRP can provide the availability of networks that have smaller delays with an average of $90.4 \mathrm{~ms}$.
\end{abstract}

Keywords: ACL, Access Control List, Packet Filtering, ACL Extended, Access List.

\section{PENDAHULUAN}

Perkembangan dunia telekomunikasi saat ini sangat pesat seiring dengan peningkatan kebutuhan layanan yang cepat dan efisien. Begitu juga dengan komunikasi data, mulai dari koneksi antar dua komputer hingga jaringan komputer. Jaringan komputer saat ini merupakan suatu layanan yang sangat dibutuhkan [1]. Jaringan komputer menjadi pilihan yang tepat baik itu perusahaan maupun personal untuk menyediakan informasi dan menghubungkann jaringan LAN ke internet. Dalam Local Area Network (LAN) diketahui bahwa setiap sistem jaringan komputer yang terhubung tidak ada jaminan sebuah keamanan [2]. Keamanan memiliki satu tujuan, untuk melindungi aset. Dengan kedatangan komputer pribadi, LAN, dan dunia internet yang terbuka lebar, jaringan saat ini lebih terbuka [3].

Sebelum tahun 90-an, jaringan internet jarang digunakan oleh masyarakat umum. Selama masa ini, keamanan belum dipertimbangkan dengan serius, namun dengan penambahan informasi yang lebih sensitif pada sebuah jaringan, hal ini akan semakin penting [4]. Salah satu upaya yang dapat dilakukan adalah dengan menerapkan access control list pada jaringan komputer. Access control list merupakan sebuah metode yang digunakan untuk menyeleksi paket-paket yang keluar masuk network [5].

Masalah keamanan termasuk dalam salah satu aspek penting dari sebuah sistem informasi, seperti pada jaringan komputer. Terhubungnya LAN (Local Area Network) atau komputer ke internet membuka potensi adanya lubang keamanan (security hole) yang membuka celah untuk merusak kinerja system [6]. ACL merupakan suatu fasilitas keamanan yang terdapat pada Cisco Internetwork Operating System (IOS) yang terdapat pada suatu perangkat router keluaran Cisco [7].

Cisco menyediakan daftar kontrol akses (ACL) untuk mengontrol arus lalu lintas dari satu antarmuka ke antarmuka lainnya dalam jaringan. ACL juga melakukan tugas-tugas lain seperti membatasi telnet, memfilter informasi routing dan memprioritaskan lalu lintas WAN dengan antrian [8]. Router bertindak sebagai filter paket saat meneruskan atau menolak paket sesuai dengan aturan penyaringan sesuai konfigurasi yang dilakukan oleh admin jaringan pada antarmuka router [9].

Penelitian mengenai ACL sudah banyak dilakukan oleh berbagai peneliti dari berbagai kalangan dengan berbagai keperluan. Begitu pula dengan penelitian mengenai perancangan keamanan jaringan menggunakan ACL. Menerapkan extended access list pada jaringan akan membantu menentukan alamat sumber dan tujuan serta protokol dan nomer port yang mengidentifikasikan aplikasi [10].

Diperlukan batasan-batasan masalah guna menentukan fokus bahasan dalam penelitian ini serta memberikan solusi dari masalah yang telah dijabarkan. Adapun batasan masalah dalam penelitian ini adalah: 1 . Implementasi metode ACL ini hanya dilakukan pada jaringan lokal saja. 2. Analisa pengaruh metode ACL pada routing EIGRP pada metode ACL. 3. Penelitian ini hanya berfokus pada packet filtering pada ACL, tidak pada service lain yang ada pada penelitian ini. 4. Implementasi metode ACL hanya akan dilakukan pada router. 
Terdapat jurnal pembanding dalam penelitian ini. Jurnal tersebut membahas tentang pengendalian lalu lintas jaringan pada ruang lingkup universitas. Ada beberapa bahasan yang terdapat pada jurnal tersebut, diantaranya sebagai berikut: 1 . server e-campus yang merupakan penyedia layanan bagi seluruh staf karyawan dan mahasiswa sehingga tidak membutuhkan pengaturan extended access list sehingga semua staf karyawan universitas serta para mahasiswa dapat mengakses website tersebut. 2. Server keuangan yang hanya dapat diakses oleh bagian keuangan.

Penerapan metode access control list pada penelitian ini bertujuan untuk mengetahui bagaimana cara kerja Extended Access List (ACL) serta pengaruh protokol EIGRP pada metode ACL. ACL akan ditempatkan pada salah satu router yang berada pada divisi 1 (router 1). Test ping akan dilakukan dari beberapa PC di divisi 1 dan divisi 2. Paket yang dikonfigurasi permit akan diizinkan melewati router 1 dan diteruskan ke PC destination, sedangkan paket yang dikonfigurasi deny akan ditolak.

\section{METODE PENELITIAN}

Diperlukan adanya studi literatur dan tinjauan pustaka untuk mendapatkan beberapa informasi dan data yang dibutuhkan, sebagai langkah untuk mencari materi pembahasan yang sesuai dengan topik yang dijadikan bahan penelitian.

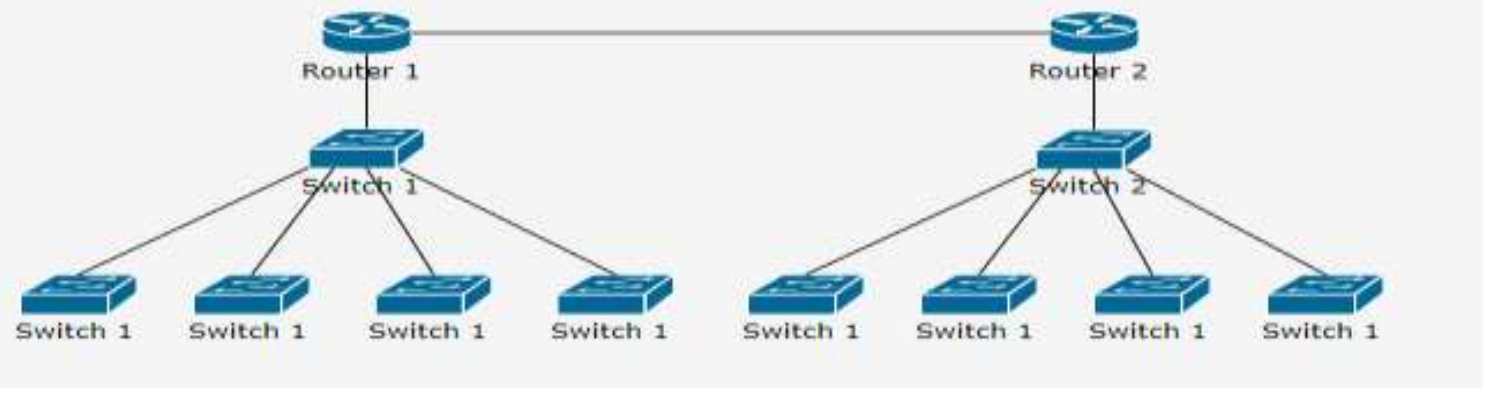

Gambar 1. Desain Topologi

Gambar 1 merupakan desain topologi yang diterapkan pada penelitian ini. Topologi tersebut nantinya akan digunakan sebagai rancangan untuk menerapkan metode Extended Access Control List (ACL), sehingga memungkinkan pengendalian network traffic pada local network.

\subsection{ACL (Access Control List)}

Access list dibagi atas dua kelompok, yaitu standard access list (1-99) dan extended access list (100-199) [6]. Standard access list dalam melakukan penyaringan paket data hanya memperhatikan alamat sumber (alamat asal) dari paket yang dikirimkan. Sedangkan extended access list mempertimbangkan antara lain adalah alamat sumber (pengirim) dan alamat tujuan (penerima) paket data, protokol dan jenis yang digunakan. Sehingga extended access list lebih spesifik dalam melakukan penyaringan paket data [5].

Access Control List (ACL) merupakan suatu metode yang diterapkan pada perangkat jaringan Cisco maupun Mikrotik. Access Control List (ACL) adalah metode yang digunakan untuk menyeleksi paket data yang akan dikirimkan dari alamat sumber (source) ke alamat yang dituju (destination). Metode access control list akan mengijinkan paket yang memiliki data permit untuk sampai pada alamat destination, sedangkan paket yang memiliki data deny akan ditolak.

\subsection{Extended ACL}

Ada dua jenis ACL yang sudah umum dikenal, yang pertama adalah standard ACL dan yang kedua adalah Extended ACL. Konsep yang dimiliki extended access control list yaitu mampu melakukan filtering pada alamat sumber (source) dan alamat tujuan (destination). Hal ini memudahkan operator jaringan dalam melakukan proses filtering dengan tujuan yang lebih spesifik. Konfigurasi akan dilakukan melalui CLI (Command Line Interface) menggunakan aplikasi terminal putty pada perangkat Cisco yang yang disimulasikan menggunakan aplikasi GNS3.

\subsection{Diagram Alur Perancangan Jaringan}

Flowchart merupakan bagan untuk menjelaskan suatu proses yang terjadi, berisi simbol-simbol tertentu yang mewakili sebuah proses yang masing-masing mempunyai arti tersendiri. Flowchart penerapan metode aceess control list extended dapat dilihat pada gambar dibawah ini. 


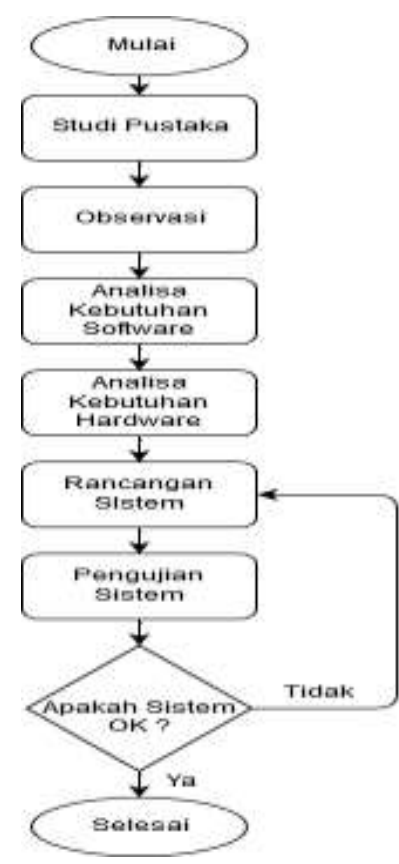

Gambar 2. Flowchart Perancangan Jaringan Menggunakan Metode Extended ACL

Penjelasan secara ringkas dari flowchart diatas adalah sebagai berikut :

a. Dimulai dari proses mencari beberapa jurnal sebagai bahan referensi pada penelitian.

b. Tahap proses pengamatan pada objek yang akan diteliti.

c. Tahap penelitian terhadap kebutuhan hardware dan software yang akan digunakan pada penelitian.

d. Tahap perancangan topologi jaringan serta mengkonfigurasi seluruh perangkat jaringan dalam penelitian.

e. Tahap pengujian sistem, apabila sistem memiliki kesalahan pada konfigurasi, maka akan dikonfigurasi ulang, dan jika kesalahan tidak terdapat pada konfigurasi maka akan kembali ke poin c yaitu pemeriksaan terhadap kebutuhan hardware dan software.

f. Tahap analisa terhadap QOS jaringan yang telah dirancang.

\subsection{Kebutuhan Hardware dan Software}

Dalam melakukan penelitian ini dibutuhkan alat pendukung perangkat keras dan lunak, diantaranya adalah :

1. Spesifikasi Perangkat Keras

Dalam melakukan penelitian ini dibutuhkan alat pendukung perangkat keras dan perangkat lunak, tabel dibawah ini adalah spesifikasi perangkat keras yang digunakan dalam melakukan penelitian ini.

Tabel 1. Spesifikasi Perangkat Keras

\begin{tabular}{lll}
\hline Perangkat & Spesifikasi Perangkat & \\
\hline Processor & Intel i-5-5200U @ 2.20GHz & \\
& $2.19 \mathrm{GHz}$ & \\
Memory & DDR3 12GB & \\
Storage & Hardisk 500GB & \\
VGA & Nvidia Geforce 930M \\
Monitor & LG-MK600 24 Inch \\
OS & Windows 10 Pro & \\
\hline
\end{tabular}

2. Software

Dibawah ini adalah software yang digunakan dalam melakukan penelitian ini.

a. GNS3

GNS3 ini digunakan sebagai software simulasi jaringan.

b. VMware

VMware berfungsi sebagai virtual server pada aplikasi GNS3, yang fungsi utamanya untuk meringankan kinerja memori dari perangkat komputer.

c. Putty

Putty berfungsi sebagai terminal CLI (Command-Line Interface) untuk memberikan konfigurasi pada seluruh perangkat jaringan.

d. Wireshark

Wireshark berfungsi sebagai software analisa pada penelitian. 
e. Cisco IOS

Cisco IOS berfungsi sebagai virtual OS pada perangkat router dan switch.

\section{HASIL DAN PEMBAHASAN}

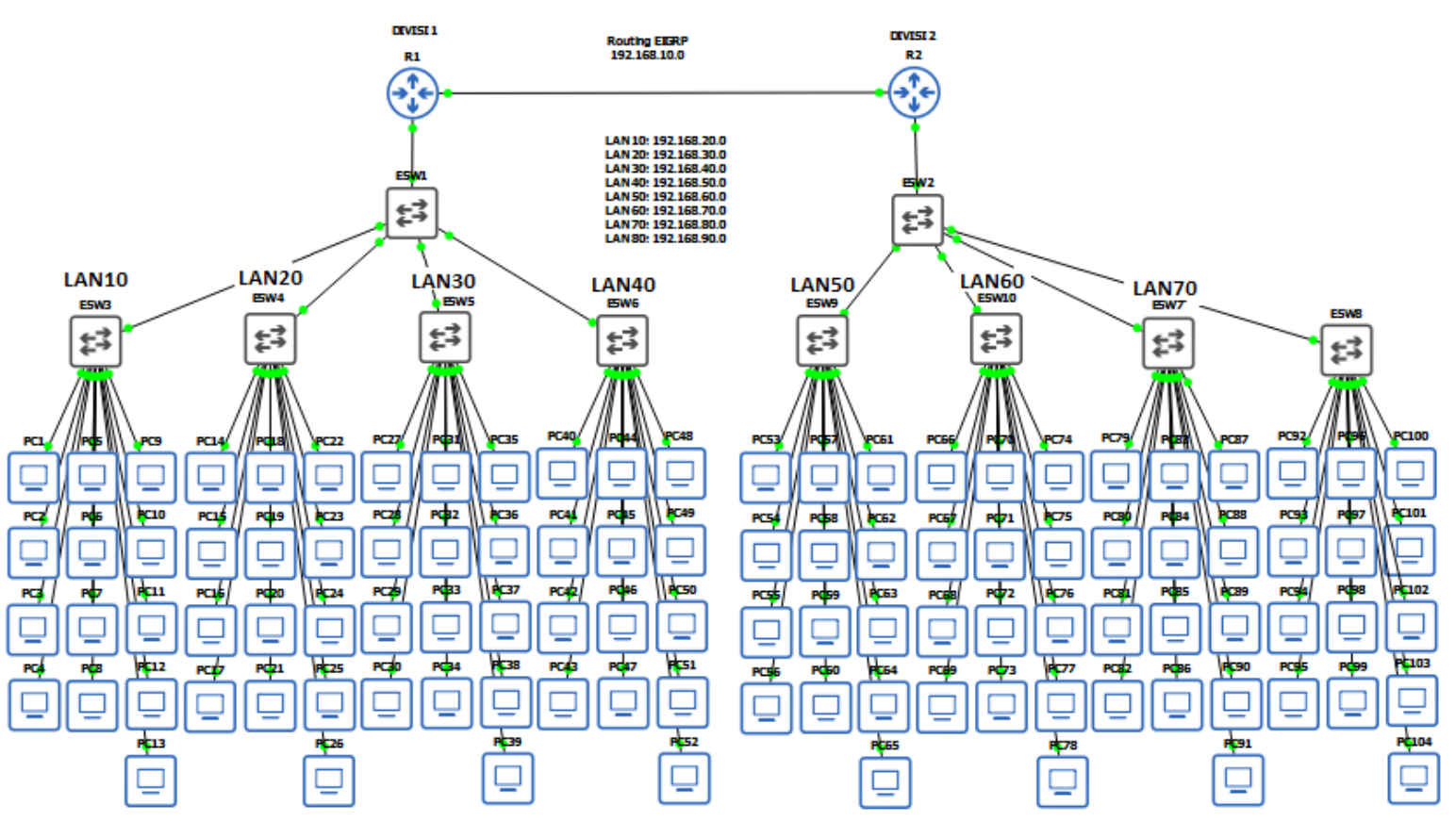

Gambar 3. Topologi Jaringan Metode ACL Extended

Dari topologi pada Gambar 3, PC pada divisi 1 (kiri) mem-blok akses paket-paket yang masuk ke divisi 2 (kanan) yang menyebabkan paket-paket tidak dapat diakses oleh divisi 2. Tetapi paket-paket yang berda pada satu divisi masih bisa melakukan akses ping terhadap PC yang lain.

\subsection{Alur Kerja Metode Extended ACL}

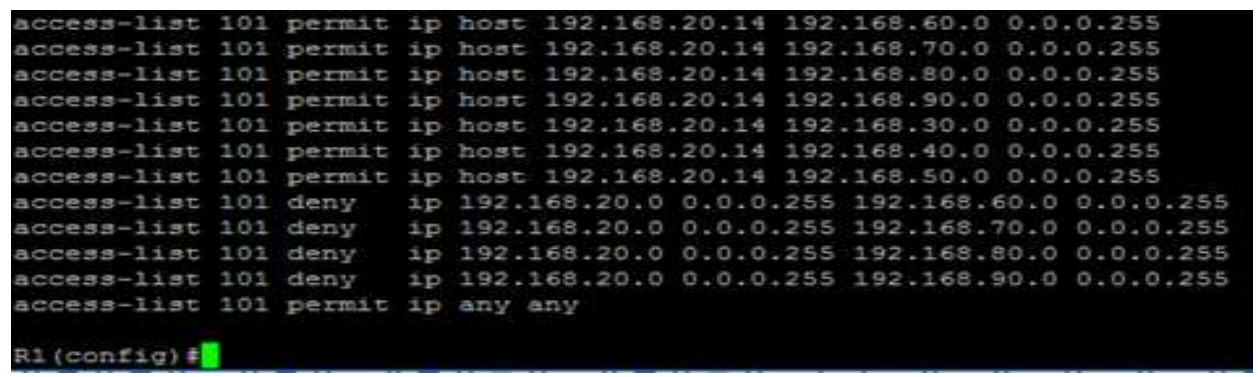

Gambar 4. Topologi Jaringan Metode ACL Extended

Perlu adanya konfugurasi ACL sebelumnya agar ACL dapat melakukan packet filtering. Konfigurasi ACL akan diletakkan pada router R1, R1 akan berperan terhadap keluar-masuknya paket. Konfigurasi pada gambar 4 merupakan data access list yang ada pada router R1. Paket dari PC source akan melakukan ping kepada PC destination. Sebelum sampai ke PC destination, paket akan masuk ke dalam inbound router R1 terlebih dahulu. Paket yang membawa protokol ICMP akan disematkan data access list yang berupa permit atau deny. Kemudian paket akan keluar dari interface router $\mathrm{R} 1$ dan menuju router $\mathrm{R} 2$, bila paket berisi permit, maka paket akan diteruskan ke PC destination, dan apabila paket berisi deny, maka paket akan didrop kembali ke PC source. Nantinya paket yang kembali melewati router R1, akan membawa pesan ICMP yang berisi (ICMP type 3, code:13, Communication administratively prohibited) yang berarti paket ditolak(deny).

\subsection{Pengujian Metode ACL Pada Divisi LAN Berbeda}

Pada tahap ini dilakukan pengujian packet filtering dengan melakukan ping packet dari PC-1 ke PC-53. Tujuan dilakukan ping packet adalah untuk memastikan apakah router $\mathrm{R} 1$ berhasil melakukan block packet terhadap PC-1 atau tidak. 


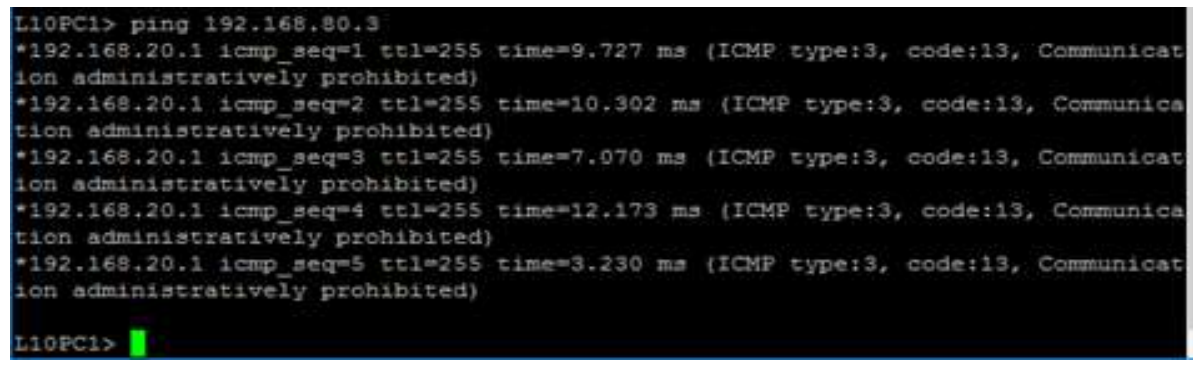

Gambar 5. Pengujian ping terhadap PC divisi 2

Dari hasil ping dapat diketahui bahwa paket yang dikirim dari PC-1 yang beralamat IP 192.168.20.2 kepada PC79 yang beralamat IP 192.168.80.2 di tolak. Ini bisa diketahui dari kode yang muncul. Kode tersebut yaitu (ICMP type 3, code:13, Communication administratively prohibited). Arti dari kode tersebut adalah, bahwa Protokol ICMP yang telah berjalan mengalami masalah, disebabkan paket yang di kirim dari PC-1 ke PC-79 ditolak.

\subsection{Pengujian Metode ACL Pada Divisi LAN Yang Sama}

Pada tahap ini dilakukan dua kali pengujian packet filtering. Pengujian pertam berupa ping packet dari PC-1 ke PC-53 yang mana Kedua PC tersebut terdapat pada LAN berbeda dan di divisi yang berbeda. Tujuan dilakukan ping packet adalah untuk memastikan apakah router $\mathrm{R} 1$ berhasil melakukan block packet terhadap packet dari PC-1 atau tidak. Dan pengujian kedua akan dilakukan pengujian ping dari PC-1 ke PC-2 yang merupakan PC yang berada pada LAN yang sama dan divisi yang sama.

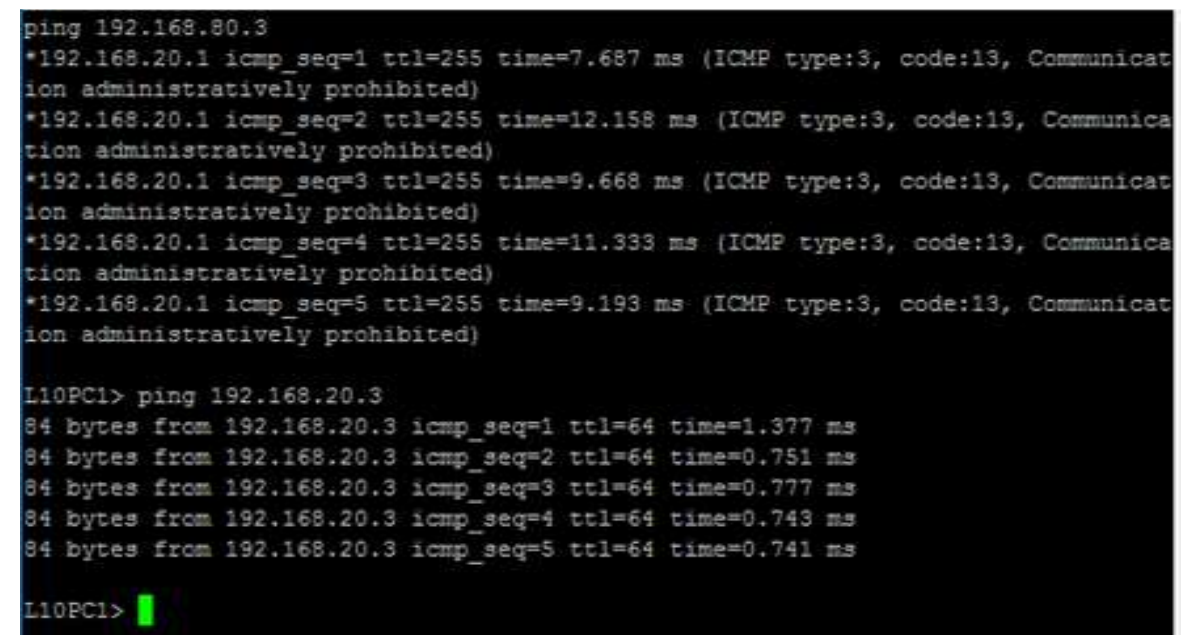

Gambar 6. Pengujian ping terhadap PC-1 di divisi 1 terhadap PC-79 di divisi 2, dan uji coba PC-1 terhadap PC2 pada LAN yang sama.

Uji coba ping dari PC-1 ke PC-79 memperoleh hasil bahwa PC-1 tidak dapat mengakses PC-79. Ini diketahui dari keterangan pada gambar yang menyatakan Communication administratively prohibited. Akses yang diketahui berasal dari alamat sumber (source) PC-1 akan dikirim berdasarkan alamat tujuan (destination). Paket yang dikirim membawa Protokol ICMP yang berisikan data access list deny (ditolak), sehingga PC-79 akan langsung men-drop paket tersebut ke alamat sumbernya dan mengirimkan informasi bahwa paket ditolak.

Berbeda halnya jika paket yang dikirimkan dari PC pada LAN yang sama yaitu PC-1 ke PC-2. Paket tersebut akan membawa protokol ICMP yang memuat data access list permit (diizinkan) ke alamat tujuan. Paket akan membawa protokol ICMP yang berisi akses di terima (permit access) menuju alamat destinasi, dan akan langsung di terima oleh alamat destinasi.

\subsection{Pengujian Metode ACL Pada PC Utama Di Beberapa LAN}

Pada pengujian tahap ini akan dilakukan ping dari PC utama kepada PC-PC yang ada pada seluruh divisi. PC utama dianalogikan sebagai PC dari pimpinan divisi yang mana dapat mengakses data-data seluruh PC. Ada beberapa pengujian pada tahap ini guna memastikan PC utama sudah mendapatkan hak akses terhadap seluruh PC. Pengujian akan diawali dengan melakukan ping packet dari PC-13 yang merupakan PC utama ke beberapa PC pada area LAN di divisi yang sama kemudian melakukan ping dari PC-13 kepada beberapa PC pada area LAN di divisi yang berbeda. 


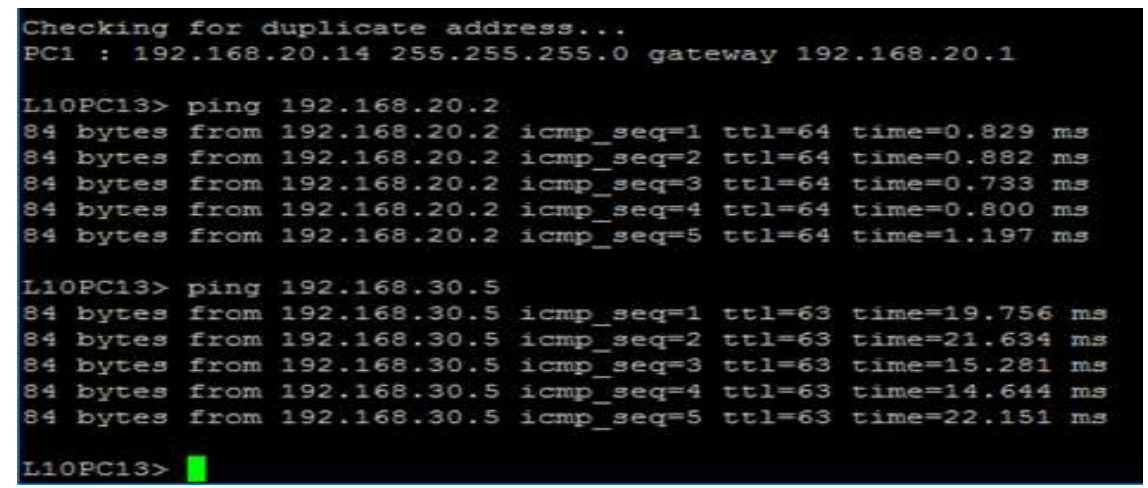

Gambar 7. Data pertama (atas) merupakan pengujian ping dari PC-13 ke PC-1 dan data kedua (bawah) merupakan pengujian ping dari PC-13 ke PC-17.

Pada pengujian ini dilakukan ping packet dari PC-13 ke PC-1 yang berada pada LAN yang sama yaitu LAN10. Kemudian dilakukan ping packet dari PC-13 ke PC-17 pada LAN20 di divisi 1. Dari Kedua pengujian ini didapatkan hasil bahwa PC-13 yang merupakan PC utama dapat mengakses data-data data dari LAN yang sama maupun berbeda dalam satu divisi.

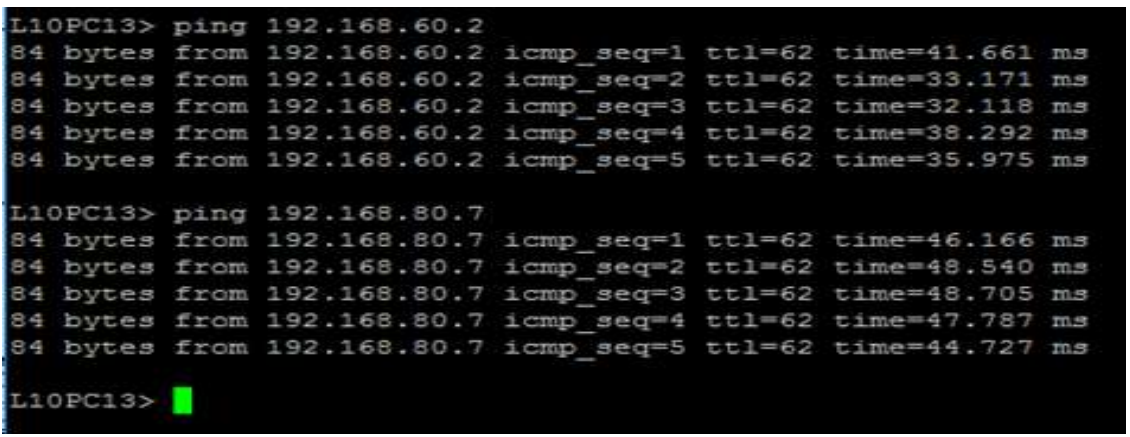

Gambar 8. Pengujian ping dari PC-13 ke PC-53 dan PC-84.

Pada pengujian ini dilakukan ping packet dari PC-13 ke PC-53 yang berada pada LAN50 di divisi 2. Kemudian dilakukan ping packet dari PC-13 ke PC-84 pada LAN70 di divisi 2. Dari Kedua pengujian ini didapatkan hasil bahwa PC-13 yang merupakan PC utama dapat mengakses data-data dari LAN pada divisi yang sama maupun divisi yang berbeda. Kebebasan hak akses diberikan karna PC utama adalah PC yang mungkin berisi informasi penting yang biasa dipakai oleh pimpinan divisi atau kepala ruangan.

\subsection{Pengujian Metode EIGRP}

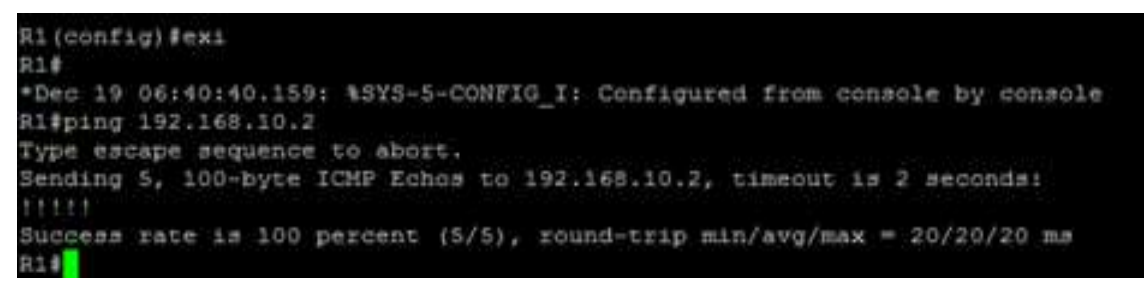

Gambar 9. Pengujian ping router R1 ke router R2 menggunakan protokol EIGRP

Pengujian EIGRP dilakukan dengan cara melakukan ping dari router R1 ke router R2. Paket yang di forward dari router R1 nantinya kanam nerima balasan dari router R2 yang berupa paket sukses terkirim kepada R2. Dari keterangan gambar diatas diperoleh bahwa ping packet kepada router $\mathrm{R} 2$ berhasil.

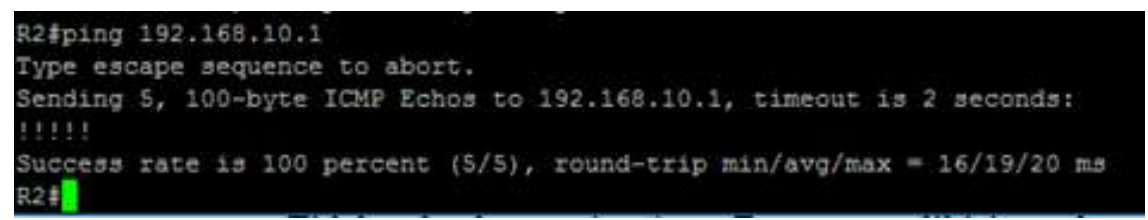

Gambar 10. Pengujian ping router R2 ke router R1 menggunakan protokol EIGRP

Pengujian EIGRP juga dilakukan pada router R2 kepada router R1. Dari keterangan gambar 10 diperoleh bahwa ping dari router R2 ke router R1 berhasil. Dengan data 100-byte menggunakan protokol ICMP. 
JURNAL MEDIA INFORMATIKA BUDIDARMA

Volume 4, Nomor 1, Januari 2020, Page 185-192

ISSN 2614-5278 (media cetak), ISSN 2548-8368 (media online)

Available Online at https://ejurnal.stmik-budidarma.ac.id/index.php/mib DOI 10.30865/mib.v4i1.1926

\subsection{Parameter QOS (Quality of Service)}

Pengujian QOS bertujuan untuk mengetahui performansi dari perancangan jaringan yang dibuat. Pengujian ini menggunakan software Wireshark. Dengan parameter yang di ujikan yaitu delay. Pengujian dilakukan sebanyak 10 kali dengan melakukan ping ke client PC pada router R2.

Tabel 2. Standarisasi Delay Berdasarkan ITU-T

\begin{tabular}{ll}
\hline Kategori Delay & Nilai $(\%)$ \\
\hline Sangat Bagus & $<150 \mathrm{~ms}$ \\
Bagus & $150-300 \mathrm{~ms}$ \\
Sedang & $300-450 \mathrm{~ms}$ \\
Buruk & $>450 \mathrm{~ms}$ \\
\hline
\end{tabular}

\subsection{Grafik Hasil Pengujian Delay}

Parameter delay dibuat untuk mengetahui seberapa besar delay yang dihasilkan dari proses konvergensi jaringan. Dari grafik pada gambar 11 dapat diketahui pada 10 PC nilai minimum delay sebesar $20 \mathrm{~ms}$ dan nilai maksimumnya adalah $15 \mathrm{~ms}$, dan rata-rata total delay adalah 90,4 ms. Ini membuktikan bahwa EIGRP adalah protokol memiliki respon time yang cepat, karena memiliki nilai delay yang kecil, sehingga memiliki konvergensi yang cepat ketika melakukan ping packet.

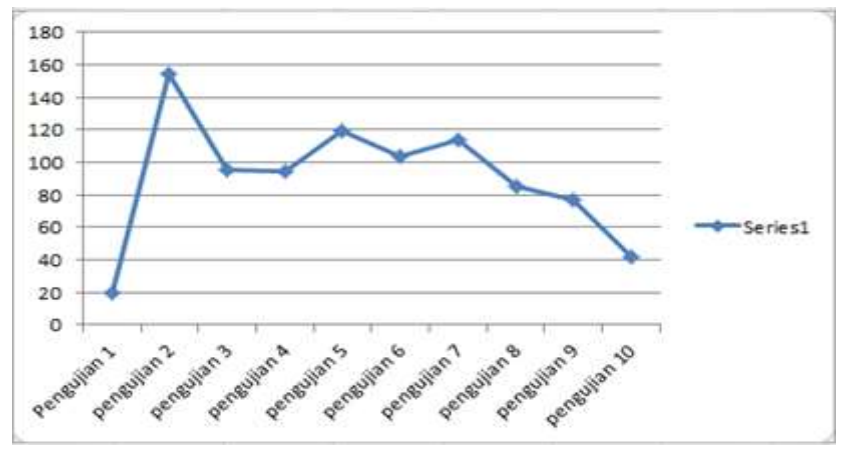

Gambar 11. Hasil Pengujian Delay

Parameter delay dibuat untuk mengetahui seberapa besar delay yang dihasilkan dari proses konvergensi jaringan. Dari grafik pada gambar 11 dapat diketahui pada 10 PC nilai minimum delay sebesar $20 \mathrm{~ms}$ dan nilai maksimumnya adalah $15 \mathrm{~ms}$, dan rata-rata total delay adalah 90,4 ms. Ini membuktikan bahwa EIGRP adalah protokol memiliki respon time yang cepat, karena memiliki nilai delay yang kecil, sehingga memiliki konvergensi yang cepat ketika melakukan ping packet.

\section{KESIMPULAN}

Berdasarkan hasil pengujian dengan memanfaatkan metode Access Control List (ACL) Extended, paket-paket yang telah di-block pada konfigurasi Access Control List (ACL) Extended tidak memiliki akses kepada ip yang telah di daftarkan. PC client pada LAN divisi 1 tidak diizinkan mengakses data pada PC divisi 2. Hanya PC utama yang di izinkan untuk mengakses seluruh jaringan. Dan dari pengujian protokol EIGRP terhadap metode ACL extended diketahui bahwa, metode ACL dapat berjalan dengan baik pada protokol EIGRP dikarenakan nilai delay-nya yang rendah, sehingga mempercepat mengiriman paket data pada seluruh PC.

\section{REFERENCES}

[1] I. Riadi, “Optimalisasi Keamanan Jaringan Menggunakan Pemfilteran Aplikasi Berbasis Mikrotik,” JUSI, vol. 1, no. 1, pp. 71-80, 2011.

[2] A. D. Purwanto and M. Badrul, "Implementasi Access List Sebagai Filter Traffict Jaringan,” J. Tek. Komput. AMIK BSI, vol. II, no. 1, pp. 78-88, 2016.

[3] S. Alabady, "Design and Implementation of a Network Security Model for Cooperative Network," Int. Arab J.e Technology, vol. 1, no. 2, pp. 26-36, 2009.

[4] D. Thelis, R. S.; Lakshani, H. G. S.; Samarawickrama, S. S.; KavinMukesh, A.; Wickramasinghe, W. A. S. M.; Dhammearatchi, "Access-Agent-Improving-The-Performance-Of-Access-Control-Lists.pdf," Int. J. Sci. Technol. RESEARCE, vol. 5, no. 04, pp. 143-150, 2016.

[5] H. A. Musril, "Extended Access List untuk Mengendalikan Trafik Jaringan," J. Edukasi dan Penelit. Inform., vol. 2, no. 2, pp. 129-135, 2016, doi: 10.26418/jp.v2i2.17436.

[6] Y. D. J. Wismoaji and I. Riadi, "ANALISIS PERANCANGAN FIREWALL PAKET FILTERING DAN PROXY SERVER UNTUK OPTIMASI BANDWIDTH (Studi Kasus di Laboratorium Riset Universitas Ahmad Dahlan Kampus 3)," JSTIE (Jurnal Sarj. Tek. Inform., vol. 3, no. 1, pp. 89-97, 2015, doi: 10.12928/jstie.v3i1.2926. 
JURNAL MEDIA INFORMATIKA BUDIDARMA

Volume 4, Nomor 1, Januari 2020, Page 185-192

ISSN 2614-5278 (media cetak), ISSN 2548-8368 (media online)

Available Online at https://ejurnal.stmik-budidarma.ac.id/index.php/mib

DOI 10.30865/mib.v4i1.1926

[7] I. Sutoyo and M. Wahyudi, "Optimalisasi Keamanan Jaringan Menggunakan Pemfilteran Aplikasi Berbasis Mikrotik," PARADIGMA, vol. XI, no. 2, pp. 110-121, 2009.

[8] S. Suman and E. A. Agrawal, "IP Traffic Management With Access Control List Using Cisco Packet Tracer," Int. J. Sci. Eng. Technol. Res., vol. 5, no. 5, pp. 1556-1561, 2016.

[9] S. K. Vishesh, S.; Tejas, C.; Tejaswini, V.; Apoorva, M.G.; Siddarth, S. B.; Samarth, "Access Control List: RouteFiltering and Traffic Control," Int. J. Adv. Res. Comput. Commun. Eng., no. 7, pp. 364-369, 2017.

[10] M. Ariq Istiqlal, L. O. Sari, and I. T. Ali, "Perancangan Sistem Keamanan Jaringan TCP/IP Berbasis Virtual LAN dan Access Control List,” Jom FTEKNIK, vol. 3, no. 1, pp. 1-9, 2016. 